\title{
A leitura pública de notícias na rede social Facebook: estudo de caso dos portais de Frutal - MG
}

\section{Public Reading of News on the social network Facebook: case study of the portals of Frutal - MG}

\section{Lectura pública de noticias em la red social Facebook: estúdio de caso de los portales de Frutal - MG}

\author{
Rodrigo Daniel Leboti Portari
}

Doutor em Comunicação pela UFMG. Coordenador do curso de Jornalismo da Universidade Estadual de Minas Gerais - UEMG - Frutal /MG - Brasil

$$
\frac{\frac{\mathrm{https}: / / \text { orcid.org/0000-0002-3196-924X }}{\mathrm{http} / / \text { lattes.cnpq.br/8795949726430425 }}}{\text { rodrigo.portari@uemg.br }}
$$

Resumo: A presente proposta teve como objetivo analisar como se dá o processo de interação e interpretação de notícias publicadas no meio on line por parte dos internautas de Frutal-MG. Foi realizada análise dos discursos apresentados na rede social para que se possa entender como se dá a relação entre o leitor e o conteúdo noticioso. Utilizamos a noção de "leitura pública" (Mouillaud, 2012) de notícias, As análises discursivas foram feitas à luz da linha francesa, buscando como autores de referência Charaudeau, Maingueneau, Pechêux e Bakhtin.

Palavras-chave: Leitura pública de notícias. Webjornalismo. Facebook.

\begin{abstract}
The present work analyzes how the process of interaction and interpretation of news published on websites by Frutal-MG Internet users takes place. The methodology adopted is that of the discursive analysis of the texts presented in the social network, in order to understand how the relationship between the reader and journalistic content occurs. We start with the theory of "public reading" (Mouillaud, 2012) of news. The discursive analyzes will be made from the French line of discursive analysis, searching as reference authors Charaudeau, Maingueneau, Pechêux and Bakhtin.
\end{abstract}

Keywords: Public Reading of News. Web Journalism. Facebook 
Resumen: La presente propuesta tuvo como objetivo analizar cómo se da el proceso de interacción e interpretación de noticias publicadas en el medio en línea por parte de los internautas de Frutal-MG. Se realizó un análisis de los discursos presentados en la red social para que se pueda entender cómo se da la relación entre el lector y el contenido noticioso. El análisis discursivo se hizo a la luz de la línea francesa, buscando como autores de referencia Charaudeau, Maingueneau, Pechêux y Bakhtin.

Palabras clave: Lectura pública de noticias. Periodismo en la red. Facebook.

\section{Introdução}

O município de Frutal-MG, localizado no Triângulo Mineiro, conta hoje com uma imprensa ativa em várias plataformas: impresso (com os jornais Pontal e Correio da Região), radiofônica (com as emissoras Rádio 97FM que veicula diariamente em três edições o "Jornal da 97"; e a Rádio Natividade 102FM que veicula em duas edições diárias o programa "Raio-X"), e na Internet, com a existência de três sites de conteúdos noticiosos: o Alô Frutal (fundado em 2013), o Pontalonline.com (fundado em 2016) e o Blog do Portari (fundado em 2011).

Dentro dessa dimensão, em anos anteriores, projetos de pesquisa elaborados no âmbito da Unidade de Frutal da UEMG analisaram o fazer jornalístico tanto do meio impresso ${ }^{1}$ como também do meio radiofônico ${ }^{2}$. Nesse período anterior as plataformas de notícias on line ainda se estruturavam no município e, apesar da existência dos portais de notícia, sua influência no âmbito da cidade ainda era limitada, assim como no resto do país, como observamos na seguinte passagem:

Em meados dos anos 90 do século XX, com o desenvolvimento da web, as tecnologias que envolvem a Internet passam a ser acessíveis tanto econômica quanto tecnicamente para a sociedade em geral. Em decorrência, ocorre a utilização em larga escala desse ambiente para usos jornalísticos, sendo que, são as versões digitais de jornais já existentes no suporte papel que se tornam mais visíveis diante do público leigo. Porém, antes do surgimento da web, a internet já era utilizada para a disseminação de informações jornalísticas. $\mathrm{Na}$ maioria dos casos, os serviços oferecidos eram direcionados para públicos muito específicos e funcionavam através da distribuição de e-mails (MIELNICZUK,2003, p. 20). 
No entanto, com o passar dos anos e a facilidade de acesso à Rede Mundial de computadores - seja por computadores, tablets, smartphones ou outros gadgets que se conectam à Internet - fez com que os portais de notícia começassem a ganhar fôlego e, mais que isso, passassem a angariar cada vez mais acessos e leitores fiéis que, atualmente, utilizam a Internet como uma das principais formas de se manter informados dos últimos acontecimentos do município.

Com o crescimento dos portais on line, hoje já é possível estabelece-los como fontes de informação importantes para a comunidade frutalense e região e, mais que isso, entender como essa mídia tem se fundamentado, divulgado informações e angariado internautas que participam ativamente da vida desses portais.

A presença desses leitores pode ser constatada mesmo em análise empírica que se faz ao observar as Fanpages (páginas on line) dos portais na rede social Facebook, uma das principais plataformas que angariam acessos a esses sites (estima-se que cerca de $60 \%$ dos usuários chegam aos portais a partir de links compartilhados ou curtidos nessa rede), como demonstra a Figura 1.

Figura 1: Captura de tela do Blog do Portari, Alô Frutal e Pontalonline.com em 27/03/2017

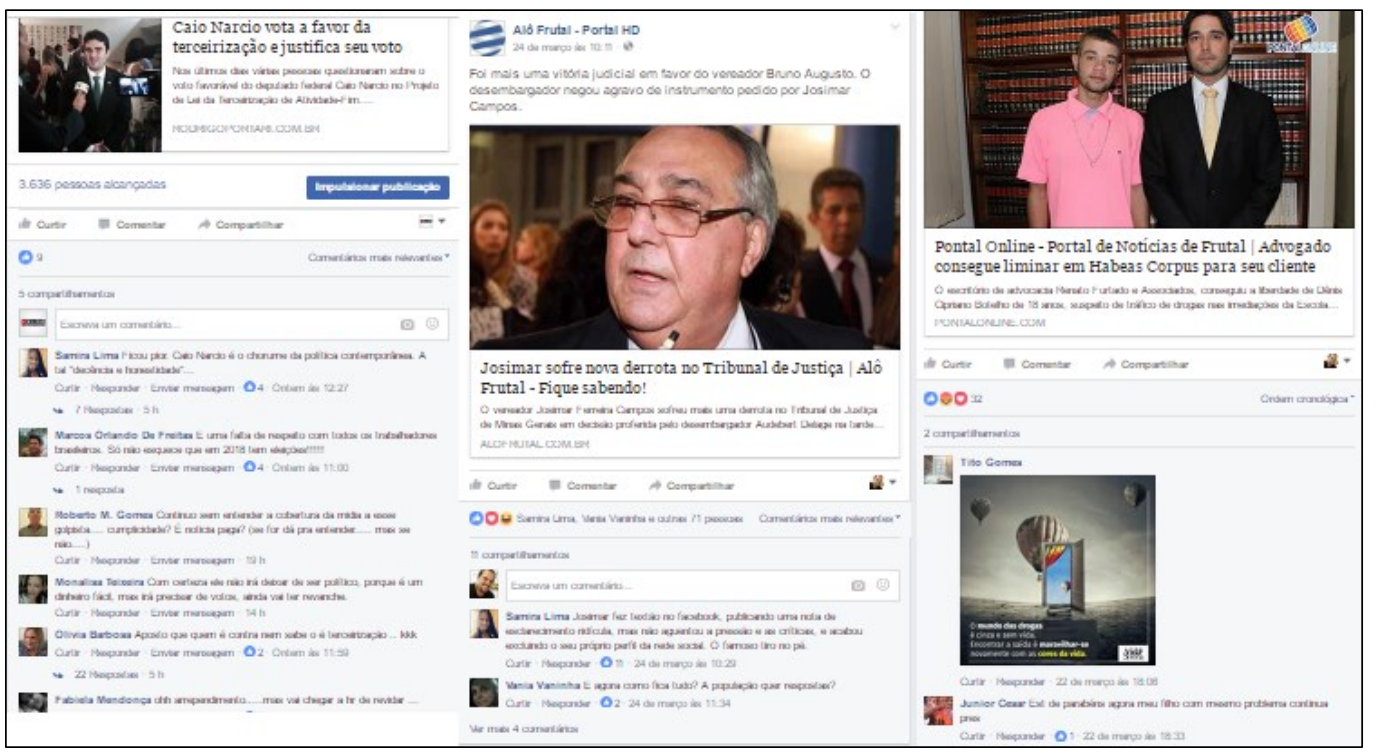

Fonte: Pesquisa documental 
Basta alguns cliques para perceber que há uma gama de leitores prontos a interagirem entre si e com os portais para discutir, criticar, elogiar ou mesmo corrigir informações que são publicadas nas páginas da rede social.

Essa é uma das características do webjornalismo ${ }^{3}$ como elencadas por Luciana Mielniczuk e João Canavilhas (2003) ao observarem como se comportam os sites de notícia na rede, sendo elas: 1) instantaneidade; 2) Interatividade; 3) Perenidade ou Memória; 4) Multimidialidade (convergência); 5) Hipertextualidade e 6) Personalização de conteúdo (customização).

De todas essas características, centraremos nossa atenção na interação dos internautas com os conteúdos compartilhados pelos portais de notícia a fim de entender como se dá essa relação e qual é o comportamento do leitor on line diante das notícias de sua cidade ou região publicadas nos portais de notícia. Vale ressaltar que mesmo nas mídias tradicionais, como o impresso, o rádio e a TV, o público sempre teve seu espaço de participação, no entanto, de forma mais fraca ou menos intensa: nos jornais há o espaço da carta dos leitores que, por limitação física, muitas vezes são editadas e selecionadas apenas algumas opiniões para que sejam publicadas; no rádio e na TV há a limitação de tempo e horário da grade de programação. E, como bem observam Primo e Trasel (2006), a participação do leitor não se dava diretamente utilizando o mesmo meio da mídia: ou era por carta ou por telefone o que, de certa forma, desestimulava também a presença do leitor nessas plataformas tradicionais.

No universo da $W e b$ essa relação é horizontal, já que tanto leitores como produtor de informação utilizam-se do mesmo meio e do mesmo espaço para emitir seus conteúdos. Essa quebra na "hierarquia" da informação permitiu e estimulou a participação dos leitores ao emitirem suas opiniões acerca dos conteúdos publicados. (BATISTA; SILVEIRA; MUNHOZ; DORNELLES, 2013)

Vale destacar, ainda que Alex Primo (2007) estabelece uma dicotomia no que tange às formas de interação mediadas pelo computador. Existiriam as (i) interações mútuas e (ii) interações reativas, sendo que o primeiro é baseado na interação de cooperação entre as pessoas conectadas à rede. Já a segunda forma de interação é provocada, no entanto, sem mudar o direcionamento dos 
conteúdos, ou seja, é limitada a clicar de um link para outro, mas sem dar a condição do usuário editar informações.

Interessante notar que, na análise empírica do material a ser estudado pelo presente projeto, a participação dos leitores em determinados assuntos os reúnem em uma espécie de comunidade virtual, ou seja, agrupam-se pessoas que têm interesses em comuns por determinados temas quando se dispõem a realizar debates e comentários das notícias. De acordo com Martino (2015, p. 44-45):

Comunidades virtuais, nas palavras de Rheingold, são uma "teia de relações pessoais" presentes no ciberespaço, formadas quando pessoas mantêm conversas sobre assuntos comuns durante um período de tempo relativamente longo. Como qualquer comunidade humana, associações virtuais se constroem a partir de laços de interesse na troca de informações. A diferença principal, no caso, está no fato desses vínculos serem formados e mantidos a partir de um computador.

Some-se a isso o fato de que o ambiente mediado pelo computador permite a conexão desses indivíduos de forma facilitada, independente da distância espacial ou mesmo temporal (um comentário de ontem pode ser novamente debatido hoje), promovendo a interação entre si e com os portais sobre assuntos que afetam o cotidiano da cidade de Frutal-MG, foco principal das informações encontradas nesses portais.

\section{Breve Histórico dos portais de notícias de Frutal - MG}

Os portais de notícia na Internet em Frutal têm uma história recente. Apesar de outras tentativas terem ocorrido no final da década de 1990 e início dos anos 2000, os sites se limitavam à transposição de conteúdos prontos produzidos por empresas jornalísticas. No entanto, a partir do ano de 2010 a realidade começa a se alterar, com o surgimento de portais específicos para a Internet, produzindo conteúdos próprios e disseminando notícias. Conforme dados levantados com os proprietários dos sites, o primeiro dos portais que se estabeleceu de forma definitiva com produção de conteúdo noticioso foi o Blog do Portari.

Fundado em abril de 2011 no formato de Blog, com a intenção de trabalhar conteúdos noticiosos e também opiniões, pouco a pouco foi se estabelecendo como 
fonte de informações, focado, especialmente em política. Foi nas eleições de 2012 que o portal começou a cair no gosto da população, disseminando notícias de bastidores que envolveram a eleição municipal daquele ano.

Já o portal Alô Frutal foi fundado no ano de 2013. Focado inicialmente em noticiário policial, seu fundador, o jornalista Edilson Luís, se valeu do fato de ser repórter do jornal Correio da Região para publicar notícias na Internet. Antes do Alô Frutal ele já havia feito outras tentativas de site de notícias. Conforme foi apurado pelos proponentes, o uso da rede social Facebook foi fundamental para que o portal pudesse se popularizar e, mais que isso, agrupar milhares de internautas em sua fanpage.

Mais recente, o portal Pontalonline.com está ligado à publicação impressa Jornal Pontal, de propriedade da Organização Franco-Brito de Comunicação, que detém também uma emissora de rádio no município de Frutal (Rádio Centenário 97FM). O portal surgiu em fevereiro de 2016 como uma resposta da publicação impressa à queda no número de leitores em virtude da popularização do Blog do Portari e Alô Frutal. Além de trabalhar com informações levantadas pelas equipes de reportagem do jornal impresso e da emissora de rádio, fez algumas tentativas de produção de conteúdo em vídeo, valendo-se da multimidialidade. Atualmente o site é abastecido pelos repórteres que atualizam seus conteúdos a partir das reportagens elaboradas para as outras plataformas.

Esse breve histórico da fundação dos portais de notícia demonstram como o webjornalismo é algo recente na história do município de Frutal-MG e ressalta-se a importância de que a Universidade, a partir de seus pesquisadores, possam acompanhar esse fenômeno midiático que está intimamente ligado, também, à popularização do acesso à Rede Mundial de computadores e, mais que isso, permitindo que uma gama cada vez maior de pessoas tenham acesso a informações noticiosas de forma gratuita.

A proposta de se estudar o leitor parte da premissa de compreender como esse internauta, agora com três portais de notícias à disposição, se comporta diante de fatos que afetam diretamente seu cotidiano.

Para isso, partimos da noção da mídia como dispositivo tal como tratada por veículo de comunicação como um dispositivo midiático na concepção de 
Antunes e Vaz (2009, p.48), para quem podemos entender a mídia como "um modo de manifestação material dos discursos; um processo de produção de significação e estruturação de sentido; uma maneira de modelar e ordenar os processos de interação; um meio de transmitir e difundir materiais significantes".

Os autores partem da noção de dispositivo de Michel Foucault para apontar que a mídia atua como agente estruturador de sentidos. Assim, há pelo menos três dimensões que merecem ser analisadas de forma aprofundada quando se pensa no estudo do jornalismo: a dimensão relacional, a dimensão contratual e a dimensão interlocutiva:

\begin{abstract}
A relacional, anel mais abrangente, diz das interações que se dão por meio do dispositivo midiático, vistas com o "processo de influências mútuas que os participantes exercem uns sobre os outros na troca comunicativa" e também o "lugar em que se exerce esse jogo de ações e reações (CHARAUDEAU, MAINGUENEAU, 2004, p.281) [...] A interlocução, por sua vez, é retomada aqui para evidenciar como os parceiros se acham, sempre, mutuamente implicados nos discursos da mídia. É um círculo contido no relacional. A dimensão de contrato é o aro mais específico, onde vemos uma linguagem funcionando sob um modo específico. (ANTUNES; VAZ, 2009, p.47)
\end{abstract}

Ao propormos o estudo da participação e comportamento do leitor diante das reportagens postadas nas redes sociais, pretende-se observar como se dá a dimensão relacional e interlocutiva da mídia on-line com seus internautas. Considerando que a mídia é agente estruturadora de sentidos, ela molda a percepção do internauta sobre o seu cotidiano e, por meio da informação noticiosa, altera a compreensão do espaço e do mundo em que ele vive.

A proposta de Antunes e Vaz (2009) é de que seja possível articular diversas relações que permitam entender a interação entre mídia e receptor, considerando que a mídia atua na produção de sentido e que esta se dá de maneira contínua, em fluxo, sem que seja possível determinar qual seria seu ponto de começo ou de encerramento ou o "marco zero" de relações hierárquicas ou que, de alguma maneira, se sobrepusessem. Como o processo de leitura e interação é sempre ativo, o internauta interpreta o conteúdo oferecido e, a partir da facilidade permitida pela Rede de Computadores, expressa opiniões, 
satisfações ou insatisfações com aquele ambiente que o cerca, promovendo a sua leitura pública dos fatos.

\section{Caminhos metodológicos}

Optamos por analisar as posturas do leitor a partir dos discursos reproduzidos na rede social Facebook por uma série de fatores que consideramos importantes para o andamento da pesquisa. Conforme destacamos, para Mouillaud (2012), os comentários desses internautas são chamados de "leitura pública" do discurso jornalístico, o que nos coloca em um terreno fértil de material a ser pesquisado, pois é neste espaço em que o leitor sai da "leitura particular" e dá retorno aos enunciados ali dispostos para ele.

Para Márcia Benetti, o ato de comentar os ocorridos na plataforma da rede social também compreende uma apropriação do discurso jornalístico: "o leitor que escreve no espaço dos comentários se apropria do discurso jornalístico e constrói, por sua vez, um novo discurso sobre o que leu" e, portanto, passa a ter também um papel ativo na dimensão relacional entre o meio (portais de notícia) e leitor.

A opção de escolher a manifestação pública na rede social também envolve critérios que são substanciais para o pesquisador, de poder chegar às impressões estampadas nos discursos dos leitores sem que estes sofram qualquer tipo de interferência pela presença do pesquisador. Neste ponto,

O leitor que se manifesta em sites de veículos e sites de redes sociais é um sujeito que se desloca da oposição que tradicionalmente lhe foi reservada ("leitor é quem lê") para ocupar outro lugar discursivo. Nesse novo lugar, ele produz sentidos sobre muitos temas; entre eles, o jornalismo. (REGINATO, 2016, p.89)

A autora acrescenta ainda características das redes sociais que propiciam a propagação da leitura pública dos internautas a partir das notícias veiculadas nessa plataforma:

Os sites de redes sociais "possuem mecanismos de individualização (personalização, construção do eu, etc.), mostram as redes sociais de cada ator de forma pública e possibilitam que os mesmos construam interações nesses sistemas" (RECUERO, 2010, p.103). Eles possibilitam a manutenção de conexões preexistentes e também o 


\begin{abstract}
estabelecimento de novas conexões, a partir de interesses compartilhados pelos indivíduos (BOYD; ELISSON, 2007), o que nos ajuda a pensar na relação entre os leitores. Embora não seja voltado especificamente para as práticas jornalísticas, um site de redes sociais pode ser apropriado por seus usuários para o jornalismo (ZAGO; RECUERO, 2011). (REGINATO, 2016, p.91)
\end{abstract}

A partir destas considerações, recorreremos à Análise de Discurso de linha francesa, considerando que o internauta como um sujeito onde sua fala reflete valores e crenças de grupos sociais, possivelmente influenciados pelo contexto em que vivem. Assim, esses sujeitos não são únicos, "mas divide o espaço de seu discurso com o outro, na medida em que, na atividade enunciativa, orienta, planeja, ajusta sua fala tendo em vista um interlocutor real, e também porque dialoga com a fala de outros sujeitos, de outros momentos históricos, em um nível interdiscursivo" (BRANDÃO, 2015, p.26).

Concordamos também com a autora que, ao recorrer a Bakhtin, destaca que a enunciação é produto da interação entre dois indivíduos e que, mesmo que não haja a presença física do interlocutor com esse internauta, seu discurso é construído pelo "representante médio do grupo social” (BAKHTIN, 1979, p.98).

Desta forma, considerando o sujeito destas falas como pessoas socialmente organizadas, em constante interação e que os discursos produzidos tendem a manifestar publicamente suas opiniões, passaremos às análises dos discursos presentes em duas situações chaves no município de Frutal: a prisão de um padre da cidade no estado de Goiás suspeito de estupro de vulnerável em junho de 2016, fato que repercutiu até mesmo nacionalmente dado à gravidade da denúncia; e a prisão de sete vereadores eleitos ocorrida em 16 de dezembro de 2016. A escolha destes recortes se deu pelo fato de estarem nos três portais e que contaram com grande número de comentários - ou leituras - dos internautas.

\title{
Comentários e leituras públicas dos internautas de Frutal - MG
}

Dois grandes fatos mobilizaram a população frutalense no ano de 2016 dada a repercussão regional e mesmo nacional dos ocorridos: a prisão do padre Fabiano Gonzaga, pároco da Igreja de Santo Antônio, no município de Caldas 
Novas (GO) em 4 de junho de 2016, após denúncia de abuso sexual de um menor de 14 anos com problemas mentais. O fato denunciado pela mãe do garoto teria sido registrado numa sauna em um clube de águas termais.

O segundo fato ocorreu em dezembro. Investigadores da Polícia Civil cumpriram mandados de prisão contra sete vereadores da cidade acusados de corrupção ativa e passiva em negociações para as eleições da Presidência da Câmara Municipal. Os três portais acompanharam os casos e produziram notícias a partir dos fatos.

Inicialmente trataremos da notícia envolvendo o padre Fabiano Gonzaga. Recortamos, entre os comentários, os que continham algum discurso a ser analisado. Assim, postagens que apenas marcavam ${ }^{4}$ outras pessoas para que tomassem ciência, bem como postagens feitas para "acompanhamento" dos comentários, foram descartadas. Restamos com enunciados que visavam exprimir a leitura ou posicionamento do internauta.

Para estabelecermos melhor a "qualificação" dos comentários relativos a esta reportagem, foi feita a seguinte divisão por categorias: comentários que "condenam" o ator principal da reportagem; que "defendem" o personagem principal; neutros ou que demonstrem espanto ou que não se dirijam diretamente à situação narrada na reportagem. Não constam no quadro 1 os comentários “descartados" como explicamos anteriormente:

Quadro 1. Quantificação de comentários relativos à reportagem sobre prisão de padre

\begin{tabular}{|c|c|c|c|c|}
\hline Portal & Condenam & Defendem & Neutros & TOTAL \\
\hline Alô Frutal & 7 & 6 & 11 & 24 \\
\hline Blog do & 10 & 5 & 1 & \\
Portari & 3 & 3 & 3 & 9 \\
\hline Pontalonline & 20 & 14 & 15 & 49 \\
\hline
\end{tabular}

Fonte: pesquisa documental

Os números demonstrados refletem a participação dos internautas. A partir da amostragem abordaremos as posturas dos leitores em seus discursos 
escritos. Dentre os principais argumentos de "condenação" do padre Fabiano estão expressões como "monstro", "padre doente", "safado" ou "tem que ir para a cadeia mesmo". São expressões encontradas nas três páginas. Demonstram a reprodução de um discurso social já enraizado e que remete, possivelmente, a expressões máximas de "bandido bom é bandido morto". O fato de a prisão ter ocorrido e as reportagens relatarem a suposta existência de testemunhas e circunstâncias que incriminam o padre é o suficiente para a rede social se transformar em um "Tribunal virtual", onde parte dos internautas (20 deles, somados os três portais), agindo como juízes, prolatam a sentença antes mesmo do esclarecimento dos fatos.

Uma vez colocada como uma sessão de júri há também os leitores que se colocam como "advogados de defesa" do acusado de estupro. Vários são os argumentos registrados, sendo que as principais expressões encontradas foram: “acredito na inocência dele", “onde estava a mãe deste adolescente?”, "não julgo ninguém”, "será que é verdade?”, “quem julga é Deus”, "não vamos pré-julgar”, "não é justo". No total, foram 14 os internautas que se manifestaram na linha defensiva, esperando a apuração para que pudessem atestar a culpa ou não do suspeito ${ }^{6}$.

As expressões neutras sobre o assunto trouxeram frases como "Meu Deus", "Misericórdia", "Marte, onde você fica?", além de "emoticons" que traduziam um rosto espantado pela reportagem. Neste caso, os 15 internautas que se manifestaram desta forma não assumiram um papel específico na leitura da reportagem.

Já o outro caso recortado demonstra, de certa forma, um padrão de leitura acerca de assuntos polêmicos que envolvam figuras públicas do município. Trata-se da prisão dos sete vereadores às vésperas da diplomação e posse para a legislatura 2017-2020. Da mesma forma, quantificamos, num primeiro momento, as reações de condenação, absolvição e neutras em relação ao fato, descartando os comentários que não expressavam conteúdo diretamente relacionado com a interpretação ou leitura pública da notícia. O quadro nos indica o que encontramos nessa análise: 
Quadro 2. Quantificação de comentários relativos à reportagem sobre prisão de padre

\begin{tabular}{|c|c|c|c|c|}
\hline Portal & Condenam & Defendem & Neutros & TOTAL \\
\hline Alô Frutal & 12 & 1 & 8 & 21 \\
\hline Blog do & 6 & 0 & 5 & 11 \\
Portari & 19 & 3 & 9 & 31 \\
\hline Pontalonline & 37 & 4 & 22 & 63 \\
\hline
\end{tabular}

Fonte: pesquisa documental

Grande volume dos comentários registrados nas páginas aponta para uma "condenação antecipada" dos vereadores. Expressões como "safados", "corruptos", "malandros", "vagabundos", “cadeia neles", "ladrões" foram repetidas nas três páginas, por diferentes pessoas, demonstrando um possível enraizamento de pensamento. Repetem discursos facilmente encontrados em comentários de portais nacionais quando o assunto é corrupção, demonstrando que o leitor dos portais de notícia do município de Frutal compartilha o discurso que prevalece - a priori - em grande parte do pensamento do brasileiro relativo a temas como este.

Dos poucos comentários defensivos, extraem-se posicionamentos como "devemos esperar a verdade aparecer", "é preciso aguardar a investigação" ou "não podemos condenar inocentes antes que tenhamos provas". São expressões utilizadas pelos poucos internautas dispostos a atuar como defensores nesta situação.

No que tange aos comentários neutros, muitos repetem expressões de espanto ou fazem referências ao cenário nacional, apontando que todo político é "ladrão" ou "vagabundo" ou ainda que a prisão ocorrida em Frutal-MG seria reflexo da Operação Lava Jato, desencadeada no âmbito federal.

Temos ilustrados, nos dois casos que as redes sociais das páginas dos sites Alô Frutal, Blog do Portari e Pontalonline.com se transformam em uma espécie de tribunal onde os internautas se colocam lado a lado com o discurso jornalístico. Mesmo que os textos publicados tendam a seguir padrões normatizados do discurso jornalístico, a leitura do internauta, transformada em discurso nos comentários, é a de que aquele conteúdo está ali para ser julgado e, desta forma, compete a ele dar a sua opinião (ou veredicto) sobre situações graves. 
Este comportamento é evidente ao se recortar dois assuntos que foram separados por aproximadamente 6 meses entre um e outro e que, a única relação entre si é o fato de se tratar de ocorrência policial envolvendo figuras públicas do município. No entanto, fica evidenciado pelo volume de comentários e pelas expressões colhidas na pesquisa a intenção deste leitor em se manifestar e colocar para o debate a sua opinião e julgamento da questão, mesmo que repetindo expressões ou pensamentos considerados "clichês" por estarem presentes por todos os cantos do país quando outros fatos com a mesma temática são publicados pela mídia nacional.

\section{Considerações Finais}

Apesar da pesquisa que originou o presente trabalho ainda estar em curso, observa-se pelos recortes selecionados que o leitor de notícias on line do município de Frutal tem interesse e faz uso da interatividade proposta pela rede social, manifestando suas expressões e suas interpretações dos conteúdos noticiosos de forma pública. Neste ponto, até o momento, percebemos que esses discursos não são dirigidos diretamente para a publicação, mas sim, para os personagens envolvidos nas notícias. Desta forma, ao se manifestarem nas redes, constroem seus textos tendo como base aquele que seria o "representante médio" do contexto social onde estão inseridos, permitindo que não haja grande problema de compreensão da mensagem a ser transmitida.

Da mesma forma, percebe-se repetição de discursos já enraizados como um todo no contexto da sociedade brasileira no que diz respeito aos dois temas selecionados para o presente trabalho: estupro de vulnerável e corrupção na política. Outros posicionamentos semelhantes foram detectados em notícias não incluídas nesta proposta, mas que, no entanto, estão elencadas como objeto de pesquisa do projeto em andamento. Espera-se a partir das análises, compreender como o leitor se posiciona a partir destes conteúdos noticiosos e como esses comentários postados em rede podem refletir a compreensão do cotidiano dos leitores, tomando como base as notícias publicadas pelos portais. 


\section{Referências}

ANTUNES, Elton; VAZ, Paulo. Mídia: um aro, um halo e um elo. In: $\mathrm{Na}$ mídia, na rua: narrativas do cotidiano. Belo Horizonte: Autêntica, p. 43-60, 2006.

BATISTA, J.; SILVEIRA, A.; MUNHOZ, L.; DORNELLES, B. As ferramentas da interatividade no webjornalismo interiorano: um retrato da participação do leitor no extremo Sul do Brasil. In: Revista GEMInINS, Ano 4 - N. 2. V.21. 2013. p.152-167.

BAKHTIN, M. Marxismo e Filosofia da Linguagem. São Paulo: Hucitec, 1979.

BRANDÃO, Helena. Enunciação e construção do sentido. In: FIGARO, Roseli (org). Comunicação e Análise do Discurso. 1 1ed. São Paulo: Contexto, 2015, (p.19-44).

CANAVILHAS, João. Webjornalismo: Considerações gerais sobre o jornalismo na web. In: I Congresso Iberoamericano de Comunicação. São Paulo, 2011. Disponível em: http://www.bocc.ubi.pt/pag/canavilhas-joao-webjornal.pdf

FRUTAL, Alô. Fanpage Alô Frutal Portal HD. Disponível em: http://www.facebook.com/alofrutalhd. Último acesso em 21 de julho de 2017.

MANHÃES, Eduardo. Análise do Discurso. In: DUARTE, Jorge; BARROS, Antônio: Métodos e Técnicas de Pesquisa em Comunicação. São Paulo: Editora Atlas, 2006.

MARTINO, Luis Mauro Sá. Teoria das Mídias Digitais: Linguagens, ambientes e redes. Rio de Janeiro: Editora Vozes, 2015.

MIELNICZUK, Luciana. Jornalismo na web: uma contribuição para o estudo do formato da notícia na escrita hipertextual. 2003. 246f. Tese (Doutorado) - Universidade Federal da Bahia, Faculdade de Comunicação, Salvador. Disponível em:

$<$ http://www.facom.ufba.br/jol/producao_teses.htm> Acesso em 15 de março de 2017. https://doi.org/10.11606/t.27.2011.tde-23092011-180325.

MIELNICZUK, Luciana. Características e Implicações do Jornalismo na Web. Disponível em:

http://www.facom.ufba.br/jol/pdf/2001_mielniczuk_caracteristicasimplicacoes.p df. Acesso: 11/03/17

MIELCZUK, Luciana. Considerações sobre a interatividade no contexto das novas mídias. Disponível via www.webjornalismo.com//sections.php?op=viewarticle\&artid=37. Acesso: $16 / 03 / 2017$ 
PALACIOS, Marcos. Jornalismo online: apontamentos para debate. Disponível

http://www.facom.ufba.br/jol/pdf/2002_palacios_informacaomemoria.pdf.

PONTALONLINE. Fanpage do portal Pontalonline.com. Disponível em: http://www.facebook.com/pontalonline. Último acesso em 21 de julho de 2017.

PORTARI, Blog. Fanpage do Blog do Portari. Disponível em: http://www.facebook.com/blogdoportari. Último acesso em 21 de julho de 2017.

PRIMO, Alex; TRÄSEL, Marcelo. Webjornalsmo participativo e a produção aberta de notícias. In: Revista Limc, 2006. Disponível em: http://www.ufrgs.br/limc/PDFs/webjornal.pdf. Acesso em 31 de março de 2017.

PRIMO, Alex . O aspecto relacional das interações na Web 2.0. E- Compós (Brasília), v. 9, p. 1-21, 2007. https://doi.org/10.30962/ec.v9i0.153

REGINATO, Gisele. As finalidades do jornalismo: o que dizem veículos, jornalistas e leitores. Tese de Doutorado defendida junto ao PPGCOM da UFRGS. Porto Alegre, UFRGS, 2016. https://doi.org/10.15448/1980-3729.2018.3.29349

Data Recebimento: 01/07/19

Data Aprovação: 29/07/19

${ }^{1}$ Projetos de pesquisa aprovados e com incentivo de bolsa PAPq foram realizados nos anos de 2013,2014 e 2015 acerca da realidade do jornalismo impresso em Frutal.

${ }^{2}$ No ano de 2016 foi conduzido projeto de pesquisa que estudou os programas Raio-X e Jornal da 97, também com incentivo de bolsa PAPq.

3 Adotamos aqui a nomenclatura de João Canavilhas no que tange às notícias divulgadas na Internet. Há algumas divergências entre autores no que tange ao nome correto a ser dado para o jornalismo praticado na Rede: "jornalismo digital", "jornalismo on line", "ciberjornalismo" ou "Webjornalismo". A adoção dessa última terminologia é pontuada por Mielniczuk (2003) como a mais adequada porque se refere ao jornalismo produzido para a plataforma "web", uma das muitas plataformas existentes na grande rede que é a Internet (FTP, SSL, Deep Web, etc.).

${ }^{4}$ No Facebook, "marcar" uma pessoa significa escrever o nome dela nos comentários para que a plataforma da rede social notifique o amigo de que foi citado em uma postagem de terceiro. Este expediente é comumente utilizado pelos internautas que desejam chamar a atenção de outra pessoa acerca de uma postagem que leu.

5 Também é comum na rede social que internautas escrevam "Ac" nos comentários de notícia com a única finalidade de ser notificado pela plataforma dos comentários de outras pessoas ou atualizações no conteúdo. As letras Ac seriam a abreviação de "Acompanhando".

${ }^{6}$ Após cerca de 12 meses a justiça de Goiás condenou o padre por estupro de vulnerável. Apesar de não termos recortado esse acontecimento para o presente trabalho, já que um dos portais não publicou a notícia, o comportamento dos internautas foi semelhante a esse primeiro momento, de 2016, com leitores reafirmando a concordância na condenação e outras ainda afirmando acreditar na inocência do padre. 